\title{
The making of mobilities in online work-learning practices
}

\section{Terrie Lynn Thompson}

University of Stirling

Stirling, Scotland UK FK9 4LA

terrielynn.thompson@stir.ac.uk

Terrie Lynn Thompson is a Lecturer in Digital Media in the Faculty of Social Sciences at the University of Stirling. Her research focuses on the digital and how professional work-learning practices and pedagogical spaces are changing globally as web and mobile technologies infuse work and everyday life routines. She is the editor of the ProPEL Matters blog (http://propelmatters.stir.ac.uk): an international cross-disciplinary network that critically debates professional practice, education, and learning.

\begin{abstract}
In this study of mobilities of work-learning practices, I draw on sociomaterial theorizing to explore how the everyday work and learning practices of contingent workers are changing through the infusion of web and mobile technologies. I use Ingold's notions of becoming and meshwork and Law's work on collateral realities to explore curation of screens, different flows of mobilities, and the importance of place to enact work-learning practices that move and mobilize. This study suggests that the making of mobilities is a fluid and provisional process that asks for a more thoughtful and critical posthuman reckoning with human-technology interactions on learning practices and spaces. I conclude with implications of these shifts in new mobilities of work-learning for workers and educators.
\end{abstract}

Keywords: sociomaterial, posthuman, mobilities, professional learning, meshwork, workspaces, digital devices, online learning

Thompson TL (2018) The making of mobilities in online work-learning practices, New Media and Society, 20 (3), pp. 1031-1046. Copyright (C) The Author 2016. Reprinted by permission of SAGE Publications. 


\section{Introduction}

The juxtaposition of new mobilities and web technologies has prompted social, geographical, economic and political imaginings. A little over a decade ago, Urry (2004: 27) made reference to the "electronic and mobile "big bang". Since then, some, such as Griffiths (2007: 1030), enthusiastically suggest that appending the concept of 'mobilities' changes everything from the texture of the everyday to privacy issues, technological innovations, governance of distribution, and user participation. Many day-to-day activities have now been 'm-ed': m-learning, mgovernment, m-retailing, and so on. Such moves illustrate what Wilson (2014: 535) describes as the infectious quality of mobile devices: 'despite their relatively recent prominence, many feel they cannot exist without' them. Interest in this field is multi-faceted and includes: human computer interaction; the mobile economy; development of mobile apps and services to move money, learning, and social development; smart cities and mobile culture; new mobile methods for research; and involvement of the masses in various forms of 'bring your own device' to crowdsourced initiatives.

This is a paper about the making of mobilities in work-learning practices and spaces. It asks: How are the everyday work-learning practices of the contingent workforce changing through the infusion of mobile and web technologies? Assumptions are often made that the combination of people and mobile devices will lead to mobilities of all kinds. But micro-analysis is needed to question what kinds of mobilities might be performed, how this unfolds, and what is actually being mobilized. Therefore, this paper conducts a sociomaterial analysis of the use of mobile devices across a range of professional work and work-related learning activities. 
Because mobility is a contested and slippery designation, it is timely to probe assumptions. Recent research offers promising directions for thinking about the fluid spaces and practices of online activities; particularly those labelled mobile. Edwards (2012: 214) argues that a focus on mobilities points us towards 'a tracing of the movements, relations and networks of things, people, discourses, information and images, and the ways in which flows are regulated, made possible, and constrained'. I draw on this conception of mobility in this paper.

This paper makes three contributions. The first is theoretical. I draw on sociomaterial perspectives to explore the relational and material mediation of practices and spaces and how "thingly gatherings serve in the performance of professional practices" (Thompson \& Adams, 2013: 342-43). Drawing on sociomaterial conceptions helps avoid one quagmire in m-learning scholarship about whether such research should focus on the mobile device or the mobile learner. Instead the focus becomes what is happening in the interweaving of human and non-human actors: a questioning of who-what is implicated in the making of mobile work-learning practices. Such posthumanist scholarship envisions humans as inseparable from the things of this world rather than the central actor and provides a way to study how the workers and web technologies in this study are co-constituted in the work-learning practices described.

Second, this theoretical framing demands different methodological sensibilities. I explore mobilities by bringing the materiality of digital devices to the fore. But not in a technologically deterministic way. As quickly evident in this study, mobility is not inherent in any one device or web app. Of interest is how negotiations between knotty tangles of actors end up enacting multiple practices and spaces as they become, move, mix, and mobilize. There is attention to the 
particular and the specific. As workers, tasks, digital entourages, knowledges, conversations, ideologies, and infrastructures are variously mobilized (and immobilized) new dilemmas emerge which demand new fluencies. In this study, focusing on the particular helps to make visible an array of practices, challenges, and dilemmas that are often invisible amidst the enthusiastic rhetoric of all things digital. Indeed, Turkle (2008: 129) acknowledges that the seduction of the 'always-on/always-on-you' tethering of humans to mobile devices has a way of taking time from other tasks, adding new tasks, and creating new kinds of time: all of which tend to be undervalued.

Third, the anytime-anywhere logic applied to working and learning on the move is challenged as the importance of place and making place is highlighted. Enriquez (2013:321) suggests that it is necessary to attend to the "materiality of "moves" ... and the relational effects of such moves to other bodies and places'. This study suggests that the making of mobilities-in learning and work practices - is a provisional process. A process that unfolds as the digital and physical infuse the other and as ideas and conversations move across devices and dispersed geographies. Examining spatial re-orderings as new mobilities of online work-learning practices are negotiated creates openings to discuss implications for work and work-related learning practices.

After outlining methodological considerations of this study, I start untangling the assortment of actors involved in ostensibly mobile work-learning practices. This includes exploring curation of screens, how mobilities and immobilities flow, and the importance of place. I maintain the hyphen in 'work-learning' throughout to signal how work and learning activities are often tightly intertwined. I draw on Ingold's notions of becoming and meshwork and Law's work on 
collateral realities. The analysis is consistent with Latour's (2005: 137) insistence on attending to the 'science only of the particular' and therefore, several everyday practices of 'mobility' are closely examined. This micro-analysis of how mobilities are made (or not) then enables consideration of how work-learning practices and spaces are changing. I conclude with implications of these shifts.

\section{Notes About Methodology}

Participants in this study were 23 contingent workers (self-employed or contract workers or micro-small entrepreneurs) from Kenya, Rwanda, and Canada. Given that online work-learning practices increasingly unfold with local, regional, and global sensibilities, participants from different geographies were recruited. In-depth interviews were conducted face-to-face (in Africa) and by telephone (Canada). Purposive sampling was used to 'select unique cases that are especially informative' and then snowball sampling as the initial participants either suggested others who might be willing to be interviewed (Neuman, 2011:268) or their data suggested other 'actors' to be followed. Some of the participants in Kenya and Rwanda were from an entrepreneurial program for young adults run by an international non-governmental organization (NGO). Interviews explored practices of engaging in global online spaces for informal workrelated learning and were 90 minutes to three hours in length, audio-recorded, and transcribed. Most participants were interviewed twice.

Data also included journals of online learning activities and learning ecology maps. The purpose of the journal was to encourage participants to become more conscious of their learning work throughout their workday. Selecting two days between the first and second interviews, participants were asked to record learning activities (informal and formal), including: what they 
did, time of day, technologies used, where they were, what prompted the activity, time spent, who else was involved, what was gained, and what they did immediately before and after the activity. A form of what Büscher et al. (2011) refer to as time-space diaries, they are well-suited to studying movements. Learning ecology maps were drawings created by participants to depict the mix of people, technologies, resources, and strategies implicated in their learning activities. Both the journals and maps were catalysts for directed conversation in the second interview and similar to Gourlay and Oliver (forthcoming) served to generate richer accounts anchored in practices. In this paper, I report on the data most germane to questions around mobilities.

Several considerations led to situating this study, in part, in Eastern Africa: the level of ICT infrastructure and mobile device usage, my familiarity working in this region, and the wellestablished programs of the NGO that provided a context for recruiting participants. Kenya is one of sub-Saharan Africa's most notable centres of technology and innovation; Rwanda has one of the most quickly developing communications infrastructures in Africa with mobile solutions at the core of their ICT initiatives (Elletson and Burgess, 2015). Kenya, in particular, has a strong mobile ecosystem. As a global leader in mobile money transfer systems, according to GSMA (2015b), $96 \%$ of the population has mobile coverage.

This study sets out to examine 'mobile' practices that move across geo-locations and is therefore, not a comparative study per se. However, practically, a starting point is required and that starting point was workers in these three countries. Space permits only brief comments about the different mobile device contexts. Across Africa, the penetration of mobile broadband is increasing, cost of devices falling, and the mobile economy considered vibrant. Yet, $60 \%$ of the 
region lacks internet access and there are significant barriers such as cost, coverage, and technical literacy for much of the population, especially in rural areas (GSMA, 2015b). According to GMSA statistics (2015a), the world average for mobile user penetration is $51 \%$ : in Sub-Saharan Africa it is $41 \%$ and $56 \%$ in Canada. Differences in how people access mobile services are also apparent. In 2014, smartphones accounted for over 70\% of connections in North America and almost 50\% of all connections were 4G (GSMA, 2015a). In contrast, $80 \%$ of mobile connections in Sub-Saharan Africa were 2G, with 4G connectivity forecast to rise to 6\% by 2020 (GSMA, 2015b).

Each of the participants in this study owned an array of mobile devices and all had self-assessed their level of digital literacy as high. Male and female participants varied from 23 to 54 years in age. Areas of work included: health care technology consultancy, ICT consultancy, mobile app development, accountancy, farming, community development, social entrepreneurship, search engine optimization writing, adult and distance education, and sessional university instruction. In this study, mobile devices in use included mobile phones, laptops, and tablet computers. I draw from Richardson's (2007: 205) description of handheld devices as ‘increasingly composite interfaces, combining the functionality of standard telephony, text-based interaction, e-mails and Internet browsing, digital video cameras, PDAs, MP3 players, and game consoles'. Although not a requirement (but not surprising), at least one mobile device accompanied participants to the interview. Having these material objects at hand, participants turned to them to demonstrate and further describe their online work-learning practices. 
Although an object—such as a mobile device — provides an entry point for a researcher, attention necessarily focuses on the 'connected' object or as Bruni (2005: 358) describes, the 'relational game in which objects are involved (and which objects themselves activate)'. In other words, the researcher attends to the sociality around the object. Mobile devices are complex actor-networks entangled with an array of other actors: data plans, bits of computer code, digital screens, YouTube videos, external hard drives, e-books, roaming charges, mobile hotspots, batteries, keyboards, Bluetooth, and server farms. To make these nonhuman actors more visible, I drew on a range of heuristics to first attune to the presences and absences of things that matter and then to analyse the materialities of various practices described. Posthuman-inspired research is cutting new methodological pathways. These heuristics provide different ways to attend to and question important nonhuman actors in one's research. Space limitations preclude further elaboration of the heuristics that guided data collection and analysis. However, they are articulated fully in Adams \& Thompson (2016), which also includes examples from the mobilities study.

\section{The Making of Mobilities}

I begin by untangling some of the thingly gatherings enacting, and enacted by, mobile worklearning practices. Complex choreographies, digital curation, hierarchies of mobility, and the coconstitutive nature of digital working and learning come to the fore. This analysis leads to a more in-depth process of tracing multiple networks of actors to examine the forces of mobilities (and immobilities). Better understanding what is happening in the meshwork of these actors highlights an array of practices that point to the importance of place in more mobile work-learning activities. By peeling back different layers, each of these three analyses surfaces various invisibilities and tensions. 


\section{Thingly Gatherings}

In Actor Network Theory (ANT) parlance, an assemblage is a gathering of actors implicated in a specific practice. An assemblage is a mix and juxtaposition of entities: a configuration of sorts. Different social relations around an object, for example, a mobile device, can lead to the enactment of different forms of mobility. The workers in this study were entangled with multiple mobile devices in multiple assemblages, often overlapping, and at times conflicting. It seemed that assemblages were enacted in particular locales and times to do particular things. Such arrangements could shift quickly, which is consistent with the provisional nature of digital artefacts. Assemblages that embraced a range of devices seemed to be valued. Wanting fewer devices in the mix was not mentioned.

The complex choreography in, and between, assemblages is striking. Makori, an ICT consultant in Kenya, shares:

I have a desktop computer, a laptop, and the phone. I don't use the desktop; it just sits in my office. I always carry my phone. My laptop is only if I'm working in a work environment. Because of a course I took I am figuring out which device is the authoritative source for specific information. So for telephone calls and numbers, my phone is the authoritative source. Although I have several contact lists, the source of that information is the phone. For email, even if it comes through the phone I never download it there, only read. I download emails on my laptop so that is the authoritative source. The laptop is also now the backup, which I do at the end of every day. I will synchronize with 
the laptop. I'm getting pressure from friends to buy an iPad. But the iPad doesn't fit. It does not work with my phone or the laptop and would just become a point of conflict.

Here the achievement of mobility—-the ability to work and learn in multiple locales—reflects a complex choreography of devices with flexibility and gaps carefully considered. This is not unusual. However, the tussle between devices provides insight into how negotiations of different material relations begin to surface more powerful actors. Ruppert et al. (2013: 40) write that material devices compete and 'those that assemble and summarize can become "centres of calculation"'. It seems Makori's phone and laptop have become centres of calculation: vital and powerful actors that assemble other actors such as contact lists and backup software. The iPad remains marginalized (for now).

In contrast, Claire's iPad has carved out an irreplaceable niche. The CEO of a mobile applications start-up in Rwanda, Claire describes her digital entourage:

It depends on what I'm doing, where I am. I can do almost everything on my mobile phone. But I always carry my iPad because it could have some information I want to share. Before my iPad I carried my PC with me. Sometimes I meet a client at a restaurant. I'll have my PowerPoint slides on my iPad and I'll make a presentation right there. If it's online I can find it on my phone. If it's a document that's not anywhere online, it's on my iPad. My iPad has replaced my iPod and e-reader and I use it to watch podcasts, read books, and take notes. When I'm traveling my iPad is the most amazing device, partly because there is always some Wi-Fi network I can access so I can do my work on the go, which is important for me. Sadly, it's an old version and I don't have the accessories. I 
don't do a lot of typing, which I wish I could do. So I do a lot of typing on my phone: mostly e-mail.

When the iPad is aligned with PowerPoint slides, podcasts, ebooks, note taking apps, and Wi-Fi networks it seems to work anywhere: a powerful actor because of its ability to enrol (and be enrolled by) others, digital or otherwise. Although new devices may replace existing ones, in this study, more often they augmented existing practices: offering slightly different options while at the same time introducing more complex choreographies. Elsewhere (Thompson, 2015) I have explored how learning ecologies are enacted through practices of curating: a piecing together, mobilizing, and tethering of digital objects and people. Here, the curation of different screens (aka devices) seems to attune to the movements of many other things: a feat that demands more work as the number of digital devices aligned with worker-learners increases.

Some of these assemblages in this study are carefully thought through: digital and human actors in purposeful alignment. Others reflect a more opportunistic hodgepodge of actors. Anderson (2012: 578) argues that parts of an assemblage do not necessarily come together by 'design or have an essential permanence that makes their connection insoluble'. So, how does this ordering unfold: who-what is doing this work? Vincent is a software tester in Kenya. The digital entourage in his surround seems to make these decisions in a way that is less directed: 'I don't decide what device to use where. It just comes automatically. I just use the nearest.' Here, the phone or laptop comes to hand when needed: anticipating and ready.

That some actors may become more powerful suggests a hierarchy of sorts. What does it take for 
a particular actor to become more prominent in the mobility hierarchy? Thus far, it seems to entail a particular array of features and accessories, ease of use, fit with other actors, and perhaps most importantly, being present at the right time. However, these regimes may be easily toppled. Despite the lack of peripheral actors that would make it more functional, Claire's iPad, having already replaced her iPod and e-reader, is now taking on some of the tasks previously performed by her laptop and phone.

Ingold's work offers insight into how humans do more than just interact with objects. Signalling a departure from ANT, Ingold (2012b: 431) argues for less focus on the 'objectness' of things and more attention to the 'material flows and formative processes wherein they come into being'. He explains that practitioners do not merely interact with their materials but rather co-respond with them: 'In the act of production, the artisan couples his own movements and gesturesindeed, his very life - with the becoming of his materials, joining with them and following the forces and flows that bring his work to fruition' (Ingold, 2012b: 435).

Co-responding with one's materials was evident in the way workers in this study seemed to couple their learning and work movements with that of mobile devices. For example, as a consultant co-responding with mobile technologies, Makori can keep his ideas close at hand, it is portable and can go everywhere with him, he can download a myriad of apps which enable him to do the things he needs to do, and it enables freedom to work outside the confines of his office. Makori's phone becomes and is a mobile device because of such forces. But his mobile phone brings flows of dependencies and vulnerabilities as well. It is only as good as its apps and power supply. It can be lost or damaged. And like most technologies, obsolescence is just around the 
corner. Indeed, once Makori sees a new (affordable) version with the "scribble" feature he stated that he will be onto the next device. A kind of digital ageism.

Such interplay of actors make the achievement of mobile work-learning practices a rather remarkable occurrence rather than a given affordance of any one device. Enacting mobile practices cannot be ascribed to devices, however powerful, and instead implicates a mish-mash

of actors. Ingold's (2012b) notion of practitioners co-responding with their materials-following their forces and flows - becomes more complicated when one considers the complexity of the gestures required to co-respond with an array of mobile materialities, often simultaneously. This is a more convoluted process of entanglement and improvisation; highlighting the complex weave of networks in action. In this respect, the notion of co-response is limiting, unless we consider the idea of multiple co-responses or take up Ingold's notion of meshwork, which I do in the next section.

\section{Forces of (Im)Mobilities}

Certain devices held up as mobile_ - phones, tablet computers (e.g., an iPad), laptops — are assumed to facilitate more and/or better forms of mobility. Claire asserts that her mobile devices have simplified her life: 'When I started my company I had to have my backpack with my computer just so I could have all the information on hand. Now I just carry my iPad and my phone'. Here, mobility is about travelling lightly. It is also about encountering the right flows of connectivity with others and ideas as needed. Note taking apps that record, store, and recall. Internet access in short bursts at exactly the right moment. Such energies enable Makori to work through his 'hot ideas' that he does not want to lose before he has a chance to develop them on 
his laptop: his ever-present mobile phone offering all sorts of invitations for 'in-the-moment' thinking and recall of those ideas. Mobile devices urge on the momentum of a thought process: simplifying interactions with other digital objects at just the right time and in just the right place.

Mobile devices are often used to pass the time while in motion, filling gaps in physical mobilities. Vincent comments:

My phone is mostly for Facebook, texting, and googling if there is nothing to do-I'm stuck in traffic on the bus and there is a problem I have to find a solution for. I don't want to bring out my Kindle or laptop in public.

It seems some mobile assemblages need to be unobtrusive, fading into the background when needed. Vincent adds:

I get on my Kindle when I'm on my way to work but coming home, if its late, I don't. When I go to the park I take out my Kindle or phone. Or a cybercafé - another secure place. Security comes first because I don't want to attract attention to my devices.

Vincent uses certain mobile devices only at certain times of the day in certain public spaces. The data shows a mobile device rendered less mobile; somehow stopped in its movement toward mobility. The making of mobilities involves presences and absences of what is on the screen, but also the screen itself. Mobile devices might not mobilize much of anything because other actors are absent. Immobilities abound: broken wireless cards confine a person to just one place; security concerns means mobile phones stay at home and are not ported around; no Wi-Fi or SIM card balance and the device, as Claire states, 'is totally useless' when on the move. Immobilities 
are differently enacted. Some might be voluntary, others temporary, enjoyable, even enforced, long-term, or troublesome (Büscher et al., 2011: 5). For Dan, a Canadian adult educator, expensive data plans and no Wi-Fi connections means he is not online when he is on the move, but this is a negotiated immobility:

I bought the cheapest plan when I got this new phone so I don't have access to data. I don't need $100 \%$ access. I'm not willing to pay the exorbitant charges. I can't get online sitting on the bus but I don't need to be online there. I can manage.

Ingold's (2012a: 49) notion of meshwork —'an entanglement of interwoven lines'—is helpful to unpick some of the many of mobilities and immobilities evident in the data. Ingold (2005: 47) has argued that instead of a network of interconnected points (or dots), 'the lines of the meshwork ... are the trails along which life is lived. And it is in the entanglement of lines, not in the connecting of points, that the mesh is constituted'. In later work, he suggests that the lines of the meshwork are the lines along which things become (Ingold, 2012a). This is an important shift. Anusas and Ingold (2013: 66) argue that it is important to move beyond 'the networked assembly of discrete objects' and instead consider the 'entangled mesh of materials in energetic movements, out of which the forms of things are continually emerging'.

How is this notion of becoming helpful in this study? By itself, a mobile phone does not make things move. Expensive data plans do not necessarily shut down working on the move. The choreography of mobilities is not just connecting devices and digital things but attuning to an assortment of moving lines and how these may intertwine: a form of meshworking. The notion of meshworking helps illuminate how ostensibly mobile practices become. In this study, ongoing 
negotiations between digital things and human actors include figuring out which device to use for what and what other digital actors or people need to be involved in order to work on the move, ensure tasks travel, or that knowledge moves. These negotiations resonate with Ingold's (2012a) idea of an improvised passage (laying the lines of the meshwork). Through these improvisations, mobilities are made. And so the choreographies described earlier might be regarded as improvisation of passages.

In improvising these passages, actors often attempt to stabilize fluid digital practices. Knots are therefore important. Ingold (2012a: 49) suggests that 'knots are places where many lines of becoming are drawn tightly together'. But lines do not simply end in a bunch of knots: for example, mobile practices do not end with a mobile phone or Wi-Fi connection or e-book. Lines (or becomings) shoot out and curve around, often overtaking the knot (Ingold, 2012a). The idea that these lines continue to cast about for other lines (Ingold 2012a) helps explain why digital practices do not always become in the same way.

But movements beyond the knot may end up tugging at it and loosening it. It is also possible that movements beyond the knot end up working themselves back into the knot: tying a double knot, so to speak. This kind of tethering could describe how particular information or connections with others are relegated to different hardware assemblages: for Makori, contact lists are tethered to his phone; backing up to his laptop. Practices that order relations between actors also reflect a degree of tethering: settling into a routine that seems efficient and effective (even if only until a new device, work task, problem, or a technology glitch such as dropped internet connectivity, data plan limits, or bandwidth restrictions come along). Having figured out what works there is a 
sense of wanting to be able to re-travel the route. Makori's dilemma about the iPad that does not fit illustrates the presence of a set of practices that have been figured out, seem to work, and are not receptive to disruption by an iPad. Perhaps attempts to tether could be considered a way of knot-making: a way to slow down movements, redirect them, or even defer them.

This sense of constancy resonates with other research. Examining postgraduate students' study practices, Gourlay and Oliver (forthcoming) found that although studying could happen 'everywhere', it was achieved only when specific combinations of space and technologies aligned. Specifically, when the technologies were stable and consistent. For example, a laptop with files that could be taken to different places. Different technologies (i.e., Wi-Fi networks, iPads, books, memory sticks, and printers) allowed different kinds of 'moorings', enabling spaces to be made and strung together, providing continuity between lecture halls and libraries, the bus and cafes, and private, personal spaces. In this respect, tethering could refer to a way of settling a passage (various lines of becoming) into a route that can be re-travelled.

\section{The (Re)Emergence of Place}

The making of mobilities does not float independently of the making of spaces. Massey (2005: 175) asserts that 'we are always, inevitably, making spaces and places'. Highlighting specific material actors of consequence has enabled an examination of how things, ideas, people, and practices flow in/through geographies (online and physical). Such analysis now helps to illuminate how mobile work-learning practices and spaces come to be, even if only in a particular moment or place. 
Makori's work-learning practices are replete with place-based negotiations (lines of movement): His desktop computer is not used and just sits in his office. His laptop is only if working onsite in a work environment. He always carries his phone and can work in his car-anywhere—because the car has a power supply. The car's power supply emanates a strong line of movement and is an important actor in how this passage (enactment of workspace) is improvised. Dan's sense of his workspaces brings other lines of movement, such as the work itself, to the fore: 'Right now I teach two university courses and tutor the UN people. I choreograph things by the nature of the work. Mondays I have certain tasks and need to be online so that determines where I have to be'.

For Neema (an accountant in Kenya), place-based negotiations enact contradictory lines of movement. She refers to herself as a 'briefcase company': not tied to an office. Neema wants to move beyond this state, as it seems to have connotations in Kenya of a less-established informal business operation. But countering that move is the way her mobile phone tugs at that knot inviting her to 'check my mail, go on every social site, do price quotations, and chat from a café, even when I'm walking around. If a client needs me at their office I can quickly say I'm walking there'. Less attached ways of working rub up against credibility that an office might confer. And so the workspace itself is very much in negotiation.

How places come to be 'practice-centred becomings', as Anderson (2012: 575) contends, helps to explain how Dan's repertoire of bus, café, kitchen table, and public library (and presence or absence of Wi-Fi connections) unfold with work practices. Other research offers insights. Sergeeva et al. (2013) explored the introduction of iPod Touch devices for use by nurses in the operating room (OR). Although meant to enable quick and accurate access to information during 
procedures, these devices unexpectedly became entangled in emailing and entertainment activities. New practices emerged in the OR, some of which were problematic as mundane and secretive material practices (to hide and shield iPod use) emerged alongside altered relations with onlookers (others in the OR not using the iPod). Polson (2015) studied how online practices of professional workers re-located to Paris were implicated in local place-making practices in order to create a sense of mobile (but not placeless) places that spanned on-and offline locales. Webpages, RSVP lists, and profile templates became entangled with organized events, reserved tables at local bars, and dinner parties to create a sense of belonging to the local scene as well as becoming part of an international community (Polson, 2015: 642): in essence, becoming the transnational professional worker through the work of place-making.

The making of place is important for mobile becomings. Places change along with what is being mobilized. Makori describes how his workspaces, work, and technological surround enact each other:

When I became a consultant I worked out my bedroom. It had all I needed: a landline phone connection, a phone, and the internet. Because $90 \%$ of my clients were foreign I never had a client that would walk into an office. I then moved into a bigger house and now my office had its own room. I had a desktop computer by then and it required more space. I also had many more books so needed space for my bookshelves. I eventually established official business premises. It's mainly for mail and staff, but not my workspace because my workspace is wherever I am. I now live in a bigger house and still have a home office. But I'm back to where I was at the start of my career: I could work from my bedroom. 
Enriquez (2013:319) argues that the focus in mobilities research should be on what is happening as practice rather than where things happen. Yet, the data in this study suggests these are not clear distinctions. The specificities of place are important to acknowledge as they become implicated in specific work-learning practices; practices that are more enmeshed with a sense of locale than acknowledged in the anytime-anywhere rhetoric. Anderson (2012: 574) argues that our activities and practices are 'not outside place or played out on place; rather, they meet and move together to form place, however provisionally'.

Forlano (2008: 39) emphasizes that in contrast to rhetoric which positions mobility as freedom, convenience, and anytime-anywhere access, mobile work (and learning) spaces are 'sites of inconvenience, constraint, and specificity'. Ben, an ICT consultant in Rwanda, experienced difficulties working on the move:

The battery in my computer has problems so I turn it on and off to save the battery which means I am always waiting for things to load. Taxis are very small so I cannot use my laptop. I used to print if I had to spend five hours in a taxi or on the bus so I can keep reading. I have been using my phone but you have to really squint because it is very small. But now that I have a tablet I know I can use it anywhere and keep my knowledge with me.

Coupling his gestures and movements of mobility with the 'becoming of his materials' (Ingold, 2012b: 435) was a bumpy path until a more mobile device (his tablet) appeared on the scene. Until then, Ben's materials were struggling to become more mobile, to co-respond with gestures 
of mobility (aka Ingold, 2012b). His workspaces were not nimble or pliable. Here we see how mobile devices do not create 'placeless places': the 'always anywhere' (Hemment, 2005: 33). The thingly configurations of specific places demand attention. Hemment (2005: 33) advocates, 'the mobility of mobile media, its freedom to roam, paradoxically leads to a reassertion of place and location'. As workers move, tasks travel, digital entourages release and tether, and knowledges circulate, the making of spaces_ — online and physical—for work and learning comes to be a highly fluid and provisional process.

Sometimes little bumps — amplified by the specificities of place-help to facilitate new ways of working on the move. Dan shares:

I had to submit a report by $4 \mathrm{pm}$ but I found myself on the far side of town. I had my laptop but also my first smartphone. I was able to send the report from my computer to my phone with Bluetooth and then I could e-mail the report to my clients through Gmail on my phone. I was in a café wondering how I was going to get to the downtown campus or go home to send this report. Although my laptop had Bluetooth I had never used it. Somehow I figured it out. My intention wasn't to experiment with Bluetooth. It was to get something done by a deadline.

A café, a deadline, and a need to coordinate Bluetooth, Gmail, a Word doc, laptop, and mobile phone demand the innovation of new work-learning practice. The thingly configuration of being stuck on a bus with limited space for your laptop (and a dodgy battery), and the equally uncomfortable scenario of squinting to read text on a small screen for hours, creates an entrée for the tablet computer. Made more visible is the work of negotiating the performance of places as 
workspaces: the very material negotiations that are necessary.

Sociomaterial theorizing affords insights into what things $d o$ and helps to make the influence of different material assemblages more visible. The complexity of the 'improvised passages' (aka Ingold 2012a) enacted by meshes of human-nonhuman actors seems to be an integral part of everyday work-learning practices in which workers, work, ways of knowing and learning, and digital things are both mobilized and immobilized. The work of these assemblages - the intertwining of various lines of movement—-highlights the relational and material textures of practices and the array of spaces in which mobile work-learning becomes.

\section{Conclusion}

This sociomaterial micro-level analysis has described specific work-learning practices in which mobile devices were prominent. It attended to things: focusing on the relationships binding human or nonhuman actors together and the effect of such connections. The workers in this study were entangled with multiple mobile devices and extensive digital entourages, resulting in overlapping and at times, conflicting practices. There was some acknowledgement of the work that these mobile assemblages demanded but these devices seemed to add more to their worklearning practices than they took away. That said, the data in this study suggests that increasingly sophisticated digital fluencies have come to matter in online work-learning practices: albeit often unnoticed and perceived as unremarkable, accepted as what has to be done, and overhead on top of other work—simply part of working, learning, playing, and living online (Thompson, 2015). To conclude, I focus on two tensions emerging from this study: the proliferation of screens and the often invisible practices enacted as workers learned to navigate multiple devices (working between screens) in order to achieve some sense of mobility in their work and work-related 
learning. With these tensions in mind, the pervasive anywhere-anytime rhetoric is challenged as implications of more mobile and mobilized learning are considered.

Law's (2011) notion of collateral realities is helpful: those realities that get done incidentally and usually unintentionally through everyday practices. Law (2011: 171) argues that by looking for 'the gaps, the aporias and the tensions between the practices and their realities', differences can be discovered. One collateral reality that becomes evident in this analysis is the work needed in order not to get lost in the commotion, contradictions, and confusion between mobile devices. Many of the sociomaterial practices around mobile devices told a similar story, despite the different geo-locations of the human participants in this study. Considerable energies were spent addressing practical things like handling back-ups, what information is kept on which device, having the right amount of redundancy between devices, figuring out how to use each new technology, and helping to coordinate how one device 'talks' to the others. These practices of choreography (and negotiation) are largely invisible and rather mundane.

In this study, mobility practices are not just about learning and working on a screen that one carries but doing so with and between multiple screens. Participants described useful worklearning mobilities as: fewer geographical constraints, increased capability to learn on the move, increased connectivities with others and their digital artefacts, and/or more extensive and timely circulations of knowledge. But does having ever more devices at hand lead to the performance of more mobile work-learning practices? Amidst the relentless saturation of the mobile market with one new thing after another, there is a significant amount of work required to order, bridge, and negotiate complex relational and material assemblages as new devices and related digital actors 
are taken on board. Although this study suggests that sorting and ordering of mobile materialities demands attention, time, and discipline (by human and technology actors), convergence on one device may not be an ideal, or even feasible, aspiration. For now, curating multiple screens may be a necessary practice for working and learning on the move.

What are the implications of these tensions? The making of mobilities in this study evoked work tasks and learning that travelled with devices; interactions that unfolded in an intricate web of physical and digital spaces and activities. It is truly a bring-your-own-devices (BYOD) scenario. Is there a role for adult educators: those who focus on workers and their (professional) learning? In this study, it was notable that educators do not figure in the work-learning spaces and practices described. Workers seem to be sorting things out on their own. This could be expected given the contingent and precarious nature of their work and workspaces. Indeed, Dron and Anderson (2014: 70) highlight the importance of multiple teaching presences in their consideration of multidimensionality online:

We dwell in multiple social spaces ... coexist[ing] on desktops and mobile devices, constantly streaming emails, tweets, instant messages, texts, RSS feeds, and site notifications.... The intersection of multiple social forms through multiple channels is among the largest new problems in social learning and puts learners in a constantly shifting range of transactional distances with, potentially, many teaching presences [emphasis added]. Prioritization and management of this multidimensional space is a central competence for the crowd-based learner. 
Perhaps much of what is being learned about mobilities of work-learning practices is crowdsourced from multiple teaching presences: a more distributed way of problem solving and circulation of knowledge. The learning department in an organization or a post-secondary educator are just two possible teaching presences and not, in this study, regarded as the 'go-to' authorities to develop these contemporary digital fluencies.

However, given that learning specialists in workplaces and formal educational institutions increasingly co-opt everyday learning practices, either as part of an offloading of responsibilities for learning to worker-learners or in attempts to make 'formal' learning encounters more 'natural', it makes sense to attune to what is going on in the everyday. Enriquez (2013:323) argues for the importance of understanding how technologies construct spaces of learning and interaction as this has implications for how educators conceive 'spaces where one might engage in learning'.

So, could learning opportunities be designed to work with the mobile practices described? Perhaps. But it will take more than just adapting existing pedagogical approaches. This study suggests that it is important not to focus merely on the device or an individual but rather both at once: together performing and bringing mobilities into being. Notions of co-constitutive practices invite different conceptions of learning spaces and places. Out of airtime, out of power, a broken device or a device that cannot access the materials, online content not optimized for mobile devices: learning possibilities are fraught with potential failure or at best, marginalized. This study offers insight into some of the ways mobile devices become knotted together with other digital things and practices. If professional learning is increasingly unfolding in ways and 
spaces described as 'mobile' and characterized by fragmentation, bite-sized learning, distractions, making do, and work arounds, then educators need to respond with truly innovative learning strategies. This is also fruitful ground for further research.

However, a critical question that needs to be asked is whether it is realistic to expect any placeany assemblage of actors - to be a learning or work space. The data in this study points strongly to the importance of place. While not denying the obvious benefits of learning and working in ways that are more flexible, accessible, and convenient it is timely to push back on the seductive logic of anywhere-anytime engagement. Perhaps what more formal learning encounters can do is create a sort of refuge: something different from the constant churning kaleidoscope of devices and spaces that need to somehow align (knot together) for things to happen. Perhaps these formal encounters are a necessary form of tethering: a making space for places and practices conducive to learning. Levy (2007) advocates for the cultivation of more contemplative practice and spaces for less frenzied activity. He writes:

[Given] today's experience of overload and acceleration, the answer would not be to prevent the proliferation of information or to slow down the pace of life ... our aim would rather be to cultivate unhurried activities and quiet places ... practices that encourage alternative habits and patterns of information production and consumption. (Levy: 234, emphasis added)

This is one possible re-ordering of mobile work-learning practices. Are there other ways educators, learning specialists, and organizational learning departments might respond to more fragmented, twitchy, mini-moments of learning? To start, there is a need to evoke discussion 
around the new digital practices outlined above. And then highlight the kinds of pedagogy — and pedagogical challenges - unfolding for adult worker-learners in and through their everyday work and learning practices. And from there, to consider new configurations of practices and spaces required meet the challenges and possibilities of more mobile and mobilized learning: learning in and through diverse, diffuse, and tenuous spaces that somehow become labelled as "learning" spaces.

\section{References}

Adams C and Thompson TL (2016) Researching a posthuman world: Interviews with digital objects. Palgrave Macmillan UK.

Anderson J (2012) Relational places: the surfed wave as assemblage and convergence.

Environment and Planning D: Society and Space 30: 570-587. doi:10.1068/d17910

Anusas M and Ingold T (2013) Designing environmental relations: From opacity to textility. Design Issues 29(4): 58-68. doi:10.1162/DESI_a_00230

Bruni A (2005) Shadowing software and clinical records: On the ethnography of non-humans and heterogeneous contexts. Organization 12: 357-378.

Buscher M, Urry J, and Witchger K (2010) Introduction: Mobile methods. In: Buscher M et al. (eds) Mobile Methods. London: Routledge, pp.1-19.

Dron J and Anderson T (2014) The distant crowd: Transactional distance and new social media literacies. International Journal of Learning and Media 4(3-4): 65.72. doi:10.1162/IJLM_a_000104

Edwards R (2012) (Im)mobilities and (dis)locating tractices in cyber-education. In: Brooks R, Fuller A and Waters J (eds) Changing Spaces of Education: New Perspectives on the Nature of Learning. Abingdon, UK: Routledge, pp.205-218. 
Elletson H and Burgess A (eds) (2015) The eLearning Africa Report 2015, ICWE: Germany

Enriquez J (2013) Being (t)here: Mobilising 'mediaspaces' of learning. Learning, Media and Technology 38(3): 319-336, doi: 10.1080/17439884.2012.685744

Forlano L (2008) Working on the move: The social and digital ecologies of mobile work places. In: Hislop D (ed) Mobility and Technology in the Workplace. Abingdon, UK: Routledge, pp.28-42.

Gourlay L and Oliver M (forthcoming) Students' physical and digital sites of study: making, marking and breaking boundaries. In: Carvalho L, Goodyear P and de Laat M (eds) Place-based spaces for networked learning. Routledge.

Griffiths M (2007) Future assemblies: Theorizing mobilities and users. New Media \& Society 9(6): 1029-1036. doi:10.1177/1461444807082698

GSMA (2015a) The mobile economy: North American 2015. Available at: https://gsmaintelligence.com/research/2015/10/the-mobile-economy-north-america$2015 / 528 /$

GSMA (2015b) The mobile economy: Sub-Saharan Africa 2015. Available at: https://gsmaintelligence.com/research/2015/10/the-mobile-economy-sub-sarahan-africa$2015 / 526 /$

Hemment D (2005) The mobile effect. Convergence: The International Journal of Research into New Media Technologies 11(2): 32-39.

Ingold T (2005) Up, Across and Along. Available at: http://spacesyntax.tudelft.nl/media/Long\%20papers\%20I/tim\%20ingold.pdf Ingold T (2012a) Looking for lines in nature. Earthlines 3: 48-51. 
Ingold T (2012b) Toward an ecology of materials. Annual Review of Sociology 41: 427-442. doi: 10.1146/annurev-anthro-081309-145920.

Latour B (2005) Reassembling the social: An introduction to actor-network theory. Oxford: Oxford University Press.

Law J (2011) Collateral Realities. In: Dominguez Rubio F and Baert P (eds) The Politics of Knowledge. London: Routledge, pp.156-188.

Levy DM (2007) Information, silence, and sanctuary. Ethics and Information Technology 9(4): $233-236$.

Neuman WL (2011) Social Research Methods: Qualitative and Quantitative Approaches $\left(7^{\text {th }}\right.$ ed.). Boston: Pearson.

Massey D (2005) For Space. London: Sage.

Polson E (2015) A gateway to the global city: Mobile place-making practices by expats. New Media \& Society 17(4): 629-645. doi: 10.1177/1461444813510135

Richardson I (2007) Pocket technospaces: The bodily incorporation of mobile media. Continuum: Journal of Media \& Cultural Studies 21(2): 205-215. doi:10.1080/10304310701269057

Ruppert E, Law J and Savage M (2013) Reassembling social science methods: The challenge of digital devices. Theory, Culture \& Society 30(1): 22-46. doi:

\section{$10.1177 / 0263276413484941$}

Sergeeva A, Huysman M, Soekijad M et al. (2013) "No user is an island” Onlookers, affordances, and the impact of mobile devices on work practices. Paper presented at International Conference on Information Systems, Milan Italy, 15-18 December.

Thompson TL (2016) Digital doings: Curating work-learning practices and ecologies. Learning, 
Media \& Technology 41(3): 480-500. doi: 10.1080/17439884.2015.1064957

Thompson TL and Adams C. (2013) Speaking with things: Encoded researchers, social data, and other posthuman concoctions. Distinktion: Scandinavian Journal of Social Theory 14(3): 342-361. doi: 10.1080/1600910X.2013.838182

Turkle S (2008) Always-on/always-on-you: The tethered self. In: Katz JE (ed) Handbook of Mobile Communication Studies. Cambridge, Mass: The MIT Press, Urry J (2004) Connections. Environment and Planning D: Society and Space 22: 27-37. doi: $10.1068 / \mathrm{d} 322 \mathrm{t}$

Wilson MW (2014) Continuous connectivity, handheld computers, and mobile spatial knowledge. Environment and Planning D: Society and Space 32: 535-555. doi:10.1068/d14112 